\title{
Exchange Rate Exposure and its Determinants: Evidence on Hungarian Firms $^{\#}$
}

\author{
Lucie Tomanová*
}

\section{Introduction}

One of the central motivations for the euro creation was to eliminate exchange rate risk. As proved by empirical studies, the common currency can result in increase in foreign trade activities. However, the existing literature at the industry or firm level finds mixed results of evidence of systematic exchange rate exposure and rarely concerns Central and Eastern European countries. This paper thus contributes to a gap of empirical findings of exchange rate volatility and its effects on firm value in the case of a transition economy. It also offers a new perspective and provides new evidence on the foreign exchange rate exposure of broad sample of firms.

The objective of this paper is to investigate the extent of exchange rate exposure in a sample of 39 companies listed in Budapest Stock Exchange during 2000 - 2014 on basis of stock prices and over a broad sample of 2037 large, medium and small firms on the cash flow basis during 2003 - 2012.

The first hypothesis tests whether the publicly listed companies or group of firms are significantly exposed to exchange rate risk. It is possible that there exists a set of conditional relationships between the explanatory variables and the exposure coefficients. If the exposure proves to be statistically significant, the next step is to identify the

\footnotetext{
\# Publication of this paper was supported by the Student Grant System of Silesian University (project SGS/7/2013). The support is gratefully acknowledged.

Ing. Lucie Tomanová - Ph.D. Student, Silesian University in Opava, School of Business Administration in Karvina, Univerzitni namesti 1394/3, 73401 Karvina, <tomanova@opf.slu.cz>.
} 
determinants that influence the exposure. This hypothesis is tested by running second-stage regressions.

The second objective of the paper is therefore to explain why some firms are exposed. To be able to understand its underlying sources, it is important to identify the determinants, or at least the characteristics, of the exchange rate exposure. The exposure coefficients estimated in the first part of the paper are used in a second-stage regression to test which factors determine exposure. The tested factors are firm's size measured as market capitalization, turnover as a proxy for liquidity and foreign sales in case of publicly listed companies and foreign sales and turnover in case of non-listed companies. These factors result from the hypothesis that the larger firms are less likely to be exposed thanks to the fact that larger firms are more likely to have resources to hedge against the exchange rate risk. However, the data on whether a firm uses hedging strategies were not available. The liquidity proxy is covered due to hypothesis that more liquid firms are most likely to be more exposed to the exchange rate risk. Foreign sales proxy is important due to the hypothesis that the more internationally active the firm is the more the firm is exposed to the exchange rate risk.

If exports are invoiced in domestic currency, the exchange rate risk is transferred to the importer. However, typically for Central and Eastern European currencies, Hungarian forint as a currency is rarely preferred as a settlement currency. Majority of exports flow to euro area countries and settlement is conducted in euro. The paper is therefore focused on the HUF/EUR exchange rate exposure, omitting other possible settlement currencies. The methodology of stock prices analysis follows the literature in defining exchange rate exposure as a statistically significant relationship between stock returns at the firm level and foreign exchange returns using orthogonalized market returns. The period under the investigation is between 01/2000 and 07/2014, which also offers the opportunity to analyze exposure during different economic stages and macroeconomic policies. The cash flow analysis offers more complex view, since studies of foreign exchange rate exposures generally use stock returns to proxy for changes in cash flows.

In this paper, we use both approaches, which allow us to understand the effect and measurement of exchange rate risk, which is then essential for possible hedging strategies. The exposures of cash flows and stock prices are related via the present value. The stock prices are measure of 
corporate performance as the present value of cash flows; however, Hungarian stock market is rather less liquid, thus the cash flow exposure estimation is essential to complete the analysis. Cash flow exposure analysis covers period from 2003 to 2012 .

The remainder of the paper is organized as follows. The literature related to exchange rate volatility and its influence on firm value is covered in Section 1. Section 2 describes methodology used to estimate cash flow exposures and provides information about the data set. The exposure estimation results and the robustness of these results are discussed in the Section 3. The paper is concluded by a summary of results in conclusion.

\section{Literature Review}

The basic understanding of exchange rate exposure is the sensitivity of a firm's market value to a change in exchange rate. In recent years, and especially after adopting rather floating exchange rate regime, exchange rate exposure has been under the scrutiny of empirical research. Starting with Adler and Dumas (1984) and Jorion (1990), studies have been undertaken on developed countries' data with rather more liquid financial markets to analyse how stock market values are affected by changes in exchange rates. Economic theory suggests that firms are subject to exchange rate exposure since their cash flows are driven by exchange rate fluctuations. Shapiro (1975) suggests that the exchange rate volatility is a major source of macroeconomic uncertainty that influences the returns and corporate cash flows.

While early empirical studies (Jorion, 1990; Bartov - Bodnar, 1994) suggested that exchange rates do not affect stock prices, the more recent studies have produced mixed results. Recent studies have demonstrated that a significant number of companies face the exchange rate exposure. Most studies have used a sample of multinational companies to test the exposure and the mixed results have been attributed to the ability to efficiently hedge against exchange rate risk from the perspective of large multinationals. Needles to say, earlier studies focused mainly on developed countries, omitting transition countries. Many studies have failed to find a relation between changes in market values and exchange rates and show insignificant effects of exchange rate changes on firm profits. Other empirical studies present rather weak relationship between 
firms' stock prices and exchange rate volatility (Dominguez - Tesar, 2006; Griffin - Stulz, 2001). The mixed results are explained by using different methodology in the papers and also different proxy for foreign exchange rate movements. Some papers use a single currency, whereas others have employed weight indices of exchange rates (Bartov - Bodnar, 1994; Jorion, 1990). Adler and Dumas (1984) have presented a single factor model to estimate foreign exchange rate exposure by estimating the elasticity of firm stock returns to exchange rate changes. The market value of a firm is constructed as the present value of future cash flows, thus the exposure can be obtained using market data that simplifies the estimation. They argue that insignificant exposure can be explained by managing the foreign exchange risks. Jorion (1990) added a variable for market movements to the model and analysed foreign exchange rate exposure of 287 U.S. multinationals over the period 1971 - 1987. Using OLS method and monthly basis data, he finds out that only $5.2 \%$ of companies is significantly exposed. In the latter paper, Choi and Prasad (1995) use similar two-factor model, but they orthogonalize the exchange rates to the market factor. They find that $14.9 \%$ (61 out of 409) of the individual firms in U.S. is significantly exposed at the $10 \%$ level. Muller and Verschoor (2006) analyse the exposure of 817 European multinational firms using OLS to estimate two-factor model by Jorion (1990), with euro's bilateral exchange rate with alternatively the US dollar, UK pound and Japanese yen as explaining variables. Their results show that about $13 \%$ of the multinational firms experienced significant exposure effects to the Japanese yen, $14 \%$ to the US dollar and $22 \%$ of firms to the UK pound.

Regarding emerging countries, many empirical studies have usually shown a significant exposure of firms. Kiymaz (2003) analysed the exposure of Turkish firms traded in Istanbul Stock Exchange over the period 1991 - 1998 using monthly-orthogonalized market return and a foreign exchange basket of US dollar and ECU. The results show that $61 \%$ of firms were highly exposed to exchange rate risk, especially those operating in textile, machinery, chemical and financial industries. The study that focused on emerging markets is by Bartram and Bodnar (2012) who analysed exposure of non-financial firms in 37 countries around the world; however, the countries of Central and Eastern Europe were not included. Their results suggest that $30-40 \%$ of firms in open and emerging market countries are significantly exposed. Chue and Cook (2008) estimated the exchange rate exposure in 15 emerging economies using GMM-IV and OLS method, excluding transition economies from 
their analysis. They have found that depreciations had negative impact on emerging market stock returns during 1999 - 2002; however, this impact significantly faded during 2002 - 2006. By using OLS method, about $40 \%$ of firms have shown significant exposure. Beyond the elasticity exposure estimation, there are papers regarding cross-sectional approach of the exposure estimates. Some studies show that the effect of exchange rate uncertainty on the firm value depends on variety of firm characteristics, including percentage of foreign sales (Jorion, 1990), according to Dukas et al., (1996) the firm size or industry concentration according Bartram and Karolyi (2006). Booth and Rotenberg (1990) show that foreign sales, foreign assets and foreign debt are amongst the determinants of the sensitivity of Canadian stock returns to the US dollar movements. Doige et al. (2002) constructed international database of over 17000 non-financial firms over a 25 -year period from 18 countries using portfolio approach. They found out that larger firms are more sensitive to currency fluctuations than smaller firms, and that the level of international sales and foreign assets are significantly negatively related to exchange rate exposure. This is in constraint with Bodnar and Wong (2003) who show that smaller firms are more exposed to foreign exchange rate movements, which is consistent with the hypothesis that larger firms have easier access to hedging strategies.

Regarding the cash flow exposures, the evidence is limited and usually conducted on a basis of case studies of individual firms. Bartram (2007) analysed exchange rate exposure of VEBA nonfinancial multinational company based on internal cash flow data. They have found that the residual net exposure is economically and statistically small, even if the operating cash flows of the firm are significantly exposed to exchange rate risk, proving the hedging activities are important key factors of the exposure reduction. According to Froot et al. (1993), higher cash flow volatility due to exchange rate risk may lead to reductions in firm value if firms face constraints on their internal financing and, as a consequence, incur either higher costs of raising external funds or opportunity costs of forgone profitable investment projects. The cash flow regressions take more of a corporate point of view where the exposure is important information for risk management in a company. 


\section{Methodology and Data}

The literature on foreign exchange rate exposure is followed by defining exposure as the relationship between excess returns and the change in the exchange as presented by Adler and Dumas (1984) who define the exposure elasticity as the change in the market value of the firm resulting from a unit change in the exchange rate. Among other studies, the advantage of this approach relies in the ability to estimate elasticity of exposure from the coefficient on the exchange rate variable. Classical framework of the exposure to exchange rate risk employs regression analysis. Foreign exchange rate exposures have been frequently estimated by the following 2 -factor model introduced by Jorion (1990):

$$
R_{i, t}=\alpha_{i}+\beta_{i} R M_{t}+\delta_{i} R_{S, t}+\varepsilon_{i, t},
$$

where $R_{i, t}$ denotes the monthly stock return of a company $i$ in period $t$,

$R M_{t}$ represents the monthly return on a market portfolio in period $t$, and $R_{S, t}$ denotes the change in the exchange rate $\operatorname{HUF} / \operatorname{EUR}(S)$ in period $t$,

$\beta_{i}$ is the firm's market beta and

$\delta_{i}$ represents the sensitivity of an $i$-th company's stock returns to exchange rate movements, interpreted as the total exchange rate exposure of a firm $i, \alpha_{i}$ is a constant,

$\varepsilon_{i, t}$ is the residual error term with zero mean and constant variance.

Positive value of $\delta i$ indicates that a depreciation of forint corresponds to an increase in the stock prices of a firm and vice versa for a negative coefficient. Equation (1) is, however, extended regression of the original model that controls for market movements used in empirical studies. The estimates of exposure coefficients could be biased due to omitted variables (Priestley and Odegaard, 2007), this problem thus motivated to include a stock market portfolio RM in the regression. The market portfolio is an aggregation of the individual firms' stocks. If the individual firms' stocks are exposed, it can be assumed that the market stock will be exposed, too. This corresponds with a view that foreign exchange rate movements are more likely to influence stock market than 
vice versa. The evidence of this issue was provided in Dumas and Solnik (1995) who showed that cross-country aggregate stock returns are affected by currencies. However, possible multicollinearity problem can be eliminated by orthogonalizing the market returns. Following Priestley and Odegaard (2007), orthogonalization of the return of market portfolio on a set of exchange rates can be done by estimating the following regression:

$$
R M_{t}=\alpha_{i} R_{S, t}+v_{m, t},
$$

where $\quad v_{m, t}$ is an error term, defined as the orthogonal market return which is not correlated with the exchange rate movements.

Therefore this variable will be used in Eq. (1) as proxy for the market returns. This approach has an advantage in simpler interpretation of the exposure coefficient as total exposure. It is important to note that the aim is to obtain a consistent estimate of the exchange rate exposure coefficient $\delta_{i}$, rather than maximize the $R^{2}$ in Eq. (1). The rather lower values of $R^{2}$ are caused by excluding all factors that can potentially affect firm's returns in Eq. (1). Eq. (1) and Eq. (3) are estimated using Ordinary Least Squares (OLS) regressions.

The availability of internal cash flow data during the period 2003 2012 allows conducting an exposure analysis using the following regression as suggested in Bartram (2007). The approach lies in regressing corporate cash flow variables on changes in exchange rates:

$$
R C F_{i, t}=\alpha_{i}+\delta_{i} R_{S, t}+\varepsilon_{i, t},
$$

where $R C F$ denotes changes in corporate cash flows of a company group $i$ in period $t$,

$R_{S, t}$ denotes the percentage change of currency $S$ in period $t$,

$\delta$ the regression coefficient captures the sensitivity of the respective cash flow to an exchange rate change and, thus, represent a measure of foreign exchange rate exposure of $i$-th group of firms. 


\subsection{The determinants of exchange rate exposure}

To identify the exposure, explanatory variables are chosen by the findings of previous studies. Most studies suggest market capitalization, turnover, foreign sales, hedging activities, liquidity, foreign debt and foreign assets. Due to the lack of available data, this analysis focuses on market capitalization as a proxy for firm's size (only in case of stock prices exposure analysis), turnover as a proxy of a firm (group of firms) $i$ 's liquidity and foreign sales as a proxy for the international trade engagement. Existing literature regarding determinants of the exchange rate exposure uses typically cross-sectional regressions of the following form to examine the determinants. The exchange rate exposure is regressed on various firm-level characteristics. Specifically, for a firm $i$, the model is estimated as:

$$
\delta_{i, n}=\varphi_{i}+\sum_{k=1}^{K} \gamma_{k} x_{i, k, n}+\varepsilon_{i, n}
$$

where $\quad \delta_{i}$ refers to the exposure of firm (group of firms in case of cash flow analysis),

$i$ to the exchange rate movements obtained from the OLS estimation of Eq. (1), resp. Eq. (3),

$\chi_{i, k}$ is firm $i$ 's $k$-th explanatory variable, and

$\varepsilon_{i}$ is a residual error term.

In particular, it is aimed to identify the reasons behind the change in exchange rate exposure of publicly listed companies across the earlier and especially later sub-period due to the higher number of significantly exposed firms. The basic regression specification includes the firm exposure coefficient estimated over the two sub-periods 2000 - 2006 and $2007-2014$ and also for the whole period as the dependent variable and market capitalization, turnover and foreign sales as explanatory variables. For the cash flows exposure determinants analysis we consider only the whole period under investigation from 2003 to 2012 due to lower frequency data using panel regressions. The limitation of methodology used in this paper is in the lower cash flow data frequency. The results are likely to be more robust when using higher frequency data. Regarding second-stage regressions, it would be also beneficial to obtain other variables that can determine the exposure, such as dummy for hedging whether a firm uses hedging strategies, dummy variable denoting whether 
the firm is a multinational corporation, dummy variable denoting whether the firm is in the traded-sector, and others. The variables were, however, not available and most firms do not publish such data. For the stock prices exposure analysis, the limits lie in the two-factor model. The other variables were not included in the regression due to the simpler interpretation of the exposure coefficient as total exposure. However, some studies use different variables, such as the value-weighted market return data, or trade-weighted exchange rates, or include other macroeconomic variables.

\subsection{Data description}

The stock prices data were obtained from Budapest Stock Exchange historical data warehouse. The data are on monthly basis (average of observations through period) from January 2000 to July 2014 including 39 companies in total, all publicly listed in the Budapest Stock Exchange. As a proxy for market returns, returns of Budapest Stock Exchange's BUX index are used. The proxy for exchange rate changes is represented by changes in HUF/EUR (direct quotation) nominal bilateral exchange rate (average of observations through period). Exchange rate data were obtained from European Central Bank's Statistical Warehouse database. Corporate cash flow data were available only on annual basis for the period from 2003 to 2012. The cash flows data are denominated in domestic currency. Unfortunately, the limitations lie in unavailability of longer period and higher frequency of data. The sample comprises of large, medium-sized and small non-financial firms which represent 8 industries: Accommodation and food service activities, agriculture, forestry and fishing; construction; electricity, gas, steam and air conditioning supply; information and communication; manufacturing; transportation and storage; wholesale and retail trade. Table 1 provides an overview of the number of firms with available cash flows data. The sample of large firms is represented by 323 firms, sample of medium sized firms is represented by 868 firms and the small sized firms' sample comprises of 846 firms. 
Tab. 1: Cash flow analysis data

\begin{tabular}{|l|r|r|r|}
\hline \multicolumn{1}{|c|}{ Industry } & \multicolumn{1}{c|}{$\begin{array}{c}\text { Large } \\
\text { firms }\end{array}$} & $\begin{array}{c}\text { Medium } \\
\text { firms }\end{array}$ & $\begin{array}{c}\text { Small } \\
\text { firms }\end{array}$ \\
\hline Accommodation and food service & 11 & 10 & 42 \\
\hline Agriculture, forestry and fishing & 0 & 44 & 56 \\
\hline Construction & 21 & 16 & 19 \\
\hline $\begin{array}{l}\text { Electricity, gas, steam and air } \\
\text { conditioning supply }\end{array}$ & 10 & 19 & 8 \\
\hline Information and communication & 15 & 64 & 87 \\
\hline Manufacturing & 99 & 428 & 251 \\
\hline Transportation and storage & 9 & 30 & 54 \\
\hline Wholesale and retail trade & 158 & 257 & 329 \\
\hline
\end{tabular}

Source: Amadeus database.

For the second-stage regression analysis, data were obtained from Budapest Stock Exchange historical data warehouse and Amadeus database. Market capitalization and turnover data are both denominated in Hungarian forint, foreign sales data are expressed as a share of foreign sales on total sales. Foreign sales are on annual basis, market capitalization and turnover data of publicly listed companies were on monthly basis, whereas the yearly data were obtained by computing the average. The firm size is specifically subject to investigation because large firms are more likely to hedge their foreign exchange risks if there are fixed costs of doing so or they might be more diversified and thus 'naturally' hedged. The proxy for firm's liquidity is turnover of a company because in case of external shocks the monetary authority allows the local currency to depreciate, stocks with relatively low liquidity tend to benefit more and vice versa.

\section{Estimation results}

\subsection{Stock prices exposure estimation results}

The individual company regressions were estimated in three periods: beginning in January 2000 and ending in July 2014 and then in two subperiods from $01 / 2000$ to $12 / 2006$ and from $01 / 2007$ to $07 / 2014$ to test for 
the persistency of exchange rate exposure. The results are presented in Table 2. In the second sub-sample, number of significantly exposed companies is significantly higher than in the period from 2000 to 2006. This can be explained preferably by the development at financial markets and higher volatility of Hungarian forint to euro during the years 2007 2009. During $2007-2014$, total of $18.4 \%$ of all companies seem to be exposed at $10 \%$ significance level.

Tab. 2: Stock prices exposure results - total exposure

\begin{tabular}{|l|c|c|c|r|}
\hline & $\begin{array}{c}\text { Sample } \\
\text { size }\end{array}$ & $\begin{array}{c}\text { Mean } \\
\text { exposure } \\
\text { coeff. }\end{array}$ & $\begin{array}{c}\text { Standard } \\
\text { Deviation }\end{array}$ & \multicolumn{2}{|c|}{$\begin{array}{c}\text { Significant } \\
\text { Exposure } \\
(\boldsymbol{\%})\end{array}$} \\
\hline Full sample & 39 & -0.4029 & 1.2386 & 4.5 \\
\hline $\mathbf{2 0 0 0}-\mathbf{2 0 0 6}$ & 22 & -0.0044 & 0.5339 & 18.4 \\
\hline $\mathbf{2 0 0 7}-\mathbf{2 0 1 4}$ & 38 & -0.6833 & 1.3897 & \\
\hline
\end{tabular}

Source: Author's calculations.

During the early sub-period, there are substantially more firms with negative exchange rate exposure than in the whole period. During $2000-$ 2006 , the number of significantly exposed firms is only $4.5 \%$, smaller percentage than in the following sub-period, mainly caused by less liquid stock market (sample size was 22 during that sub-period) and also due to the fact that only companies with good resources to hedge against exchange rate risk participated in stock market. Nevertheless, also in the following sub-period companies surely used hedging strategies, however, the situation in the global economy was rather less predictable. The mean exposure coefficient for all periods remained negative. Apart from quite high level of exposure, results demonstrate that effects of exchange rate are mostly negative. Most of the companies show negative exposure coefficient, therefore depreciation of domestic currency corresponds with a decrease of firm's stock returns. The results are in constraint with other studies regarding emerging markets (i.e. Kiymaz, 2003; Bartram Bodnar, 2012; Chue - Cook, 2008) which usually find higher percentage of the significantly exposed firms. However, there is a lack of existing empirical evidence on central and eastern European countries, thus the empirical results are more difficult to compare. 
Regarding the exposure determinants, if $\gamma$ is negative for a particular firm-level explanatory variable, an increase in this variable will make exchange rate depreciation more damaging for the firm's value. The results of the cross-sectional regressions are presented in Tab. 3. Using panel regression in three periods, the results support for the market capitalization and foreign sales as important determinants of the exchange rate exposure of firms. These results are consistent with Jorion (1990) and Dukas et al. (1996). However, only in the later sub-period the hypothesis of both, the foreign sales and market capitalization, as important determinants were confirmed as significant factors. However, the coefficients are very close to zero. For the full sample 2000 - 2014 only foreign sales significantly determined the foreign exchange rate exposure which is also consistent with theoretical expectations. In the early subperiod it none of the variables seemed to have impact on exchange rate exposure. The results are not very robust due to the low R-squared values, $14,10 \%$ in case of early sub-period, $16,47 \%$ in case of later sub-period and $19,47 \%$ in case of the full sample. In the later sub-period, there is a negative relationship between a firm's exchange rate exposure and its level of foreign sales and market capitalization. By contrast, in the all sample period, the market capitalization has positive slope and is not statistically significant. The turnover as a determinant of exchange rate exposure has weak support in this analysis since in all cases it has proved as insignificant.

Tab. 3: Stock prices exposure results - determinants

\begin{tabular}{|l|c|c|c|}
\hline \multicolumn{1}{|c|}{ Industry } & $\mathbf{2 0 0 0}-\mathbf{2 0 0 6}$ & $\mathbf{2 0 0 7}-\mathbf{2 0 1 4}$ & $\mathbf{2 0 0 0}-\mathbf{2 0 1 4}$ \\
\hline \multirow{2}{*}{ Constant } & 0.3123 & 0.4311 & 0.3244 \\
& {$[2.0331]$} & {$[1.5887]$} & {$[2.1499]$} \\
\hline Market & 0.0510 & -0.0011 & 0.0034 \\
Capitalization & {$[0.0331]$} & {$[-2.0231]$} & {$[1.0870]$} \\
\hline \multirow{2}{*}{ Turnover } & 0.0841 & 0.0881 & -0.0023 \\
& {$[0.0572]$} & {$[1.0897]$} & {$[-1.0099]$} \\
\hline \multirow{2}{*}{ Foreign Sales } & -0.0153 & -0.0041 & -0.0073 \\
& {$[-0.0581]$} & {$[-2.1427]$} & {$[-2.0132]$} \\
\hline R-squared & 0.1410 & 0.1647 & 0.1947 \\
\hline
\end{tabular}

Source: Author's calculations. 


\subsection{Cash flow exposure estimation results}

The estimation results for Hungarian firms are reported in Tab. 4. In the sample of Hungarian firms we find that the response of cash flows to exchange rate fluctuations is mostly negative which is consistent with the stock prices analysis results. The significant cash flow exposure is present in a group of large firms operating in manufacturing industry and in wholesale and retail trade industry. The exposure coefficients in these cases are both positive and negative, meaning that the depreciation of Hungarian forint is connected with an increase in company's cash flow in case of manufacturing industry and decrease in case of wholesale and retail trade industry. Results showed that medium sized companies' exposure coefficients are not statistically significant in most cases. The only exceptions are the accommodation and food service activities industry and agriculture, forest and fishing industry.

Tab. 4: Cash flow exposure results - total exposure

\begin{tabular}{|l|c|c|c|c|}
\hline \multicolumn{1}{|l|}{ Industry and size } & Intercept & $\begin{array}{c}\text { Exposure } \\
\text { coeff. }\end{array}$ & R2 & D-W \\
\hline $\begin{array}{l}\text { Large } \\
\text { accommodation }\end{array}$ & $2.4591 * *$ & -0.1174 & 0.1974 & 2.4 \\
\hline Large agriculture & - & - & - & - \\
\hline Large construction & 0.8942 & -0.0233 & 0.3948 & 2.3 \\
\hline Large electricity & 0.5708 & 0.0187 & 0.2190 & 2.0 \\
\hline Large ICT & $0.4612^{*}$ & -0.0170 & 0.2933 & 2.3 \\
\hline $\begin{array}{l}\text { Large } \\
\text { manufacturing }\end{array}$ & 2.1061 & $0.2872 * *$ & 0.1166 & 2.2 \\
\hline $\begin{array}{l}\text { Large } \\
\text { transportation and } \\
\text { storage }\end{array}$ & $0.5443^{* *}$ & 0.0194 & 0.1694 & 2.3 \\
\hline $\begin{array}{l}\text { Large wholesale } \\
\text { and retail trade }\end{array}$ & $1.1953 *$ & $-0.0928^{*}$ & 0.1471 & 2.2 \\
\hline $\begin{array}{l}\text { Medium } \\
\text { accommodation }\end{array}$ & 0.6302 & $0.1166^{* *}$ & 0.1844 & 2.2 \\
\hline $\begin{array}{l}\text { Medium } \\
\text { agriculture }\end{array}$ & $2.4392^{*}$ & $-0.1431^{*}$ & 0.2805 & 2.4 \\
\hline $\begin{array}{l}\text { Medium } \\
\text { construction }\end{array}$ & 0.4828 & 0.0224 & 0.0777 & 2.3 \\
\hline
\end{tabular}




\begin{tabular}{|l|c|c|c|c|}
\hline Industry and size & Intercept & $\begin{array}{c}\text { Exposure } \\
\text { coeff. }\end{array}$ & R2 & D-W \\
\hline Medium electricity & 0.3169 & -0.0487 & 0.1486 & 2.4 \\
\hline Medium ICT & 0.4413 & -0.0472 & 0.1671 & 2.3 \\
\hline $\begin{array}{l}\text { Medium } \\
\text { manufacturing }\end{array}$ & $0.7216^{*}$ & -0.0208 & 0.1353 & 2.4 \\
\hline $\begin{array}{l}\text { Medium } \\
\text { transportation and } \\
\text { storage }\end{array}$ & $2.1317^{*}$ & -0.0604 & 0.4453 & 2.0 \\
\hline $\begin{array}{l}\text { Medium wholesale } \\
\text { and retail trade }\end{array}$ & $0.5244^{*}$ & 0.0180 & 0.2166 & 2,3 \\
\hline $\begin{array}{l}\text { Small } \\
\text { accommodation }\end{array}$ & $0.4713^{* *}$ & -0.0451 & 0.1762 & 2.5 \\
\hline Small agriculture & $0.4632^{* *}$ & 0.0235 & 0.1928 & 2.4 \\
\hline Small construction & $0.9705^{*}$ & 0.0386 & 0.7781 & 2.1 \\
\hline Small electricity & $0.5732^{*}$ & -0.0547 & 0.1320 & 2.4 \\
\hline Small ICT & $0.4139 * *$ & -0.0217 & 0.1752 & 2.3 \\
\hline $\begin{array}{l}\text { Small } \\
\text { manufacturing }\end{array}$ & $0.5867 * *$ & -0.0055 & 0.0963 & 2.0 \\
\hline $\begin{array}{l}\text { Small } \\
\text { transportation and } \\
\text { storage }\end{array}$ & $2.6971 *$ & $-0.0388^{* *}$ & 0.4098 & 2.1 \\
\hline $\begin{array}{l}\text { Small wholesale } \\
\text { and retail trade }\end{array}$ & 0.9634 & $0.0829 * *$ & 0.1424 & 1.6 \\
\hline
\end{tabular}

Source: Author's calculations.

Notes: * denotes $5 \%$ significance level, $* *$ denotes $10 \%$ significance level

Small firms operating in transportation and storage industry show negative significant exchange rate exposure coefficient, whilst wholesale and retail trade industry has positive significant coefficient. Medium sized and small sized companies have negative exposure coefficients in majority of industries. These firms thus suffer more from the exchange rate volatility than larger firms. Results showed that Hungary has highest number of significantly exposed firms (34\%), which is consistent with recent studies (Bartram - Bodnar, 2007; Chue - Cook, 2008) estimating exchange rate exposure in emerging markets. Due to significantly exposed large firms operating in manufacturing and wholesale and retail trade activities, it seems that $79 \%$ of firms from large firms group are significantly exposed. It would be thus beneficiary to obtain data from more firms operating in other industries due to possible overage of the 
percentage resulted from insufficient number of observations in different industries. Small firms group analysis resulted in $45.27 \%$ significantly exposed firms which is consistent with assumption that smaller firms will have less resources to hedge against the exchange rate risk.

Tab. 5: Cash flow exposure results - determinants

\begin{tabular}{|l|r|r|r|r|}
\hline \multicolumn{1}{|c|}{ Industry } & Foreign sales & \multicolumn{1}{c|}{ Prob. } & Turnover & Prob. \\
\hline $\begin{array}{l}\text { Large } \\
\text { Manufacturing }\end{array}$ & 0.0004 & 0.0082 & 0.0017 & 0.0294 \\
\hline $\begin{array}{l}\text { Large Wholesale } \\
\text { and retail trade }\end{array}$ & -0.0009 & 0.0182 & 0.0003 & 0.0000 \\
\hline $\begin{array}{l}\text { Medium } \\
\text { Accommodation } \\
\text { and food service }\end{array}$ & -0.0008 & 0.1699 & 0.0001 & 0.1383 \\
\hline $\begin{array}{l}\text { Medium } \\
\text { agriculture, } \\
\text { forestry and } \\
\text { fishing }\end{array}$ & 0.0007 & 0.1811 & 0.0001 & 0.1383 \\
\hline $\begin{array}{l}\text { Small Wholesale } \\
\text { and retail trade }\end{array}$ & 0.0005 & 0.1469 & -0.0003 & 0.0000 \\
\hline
\end{tabular}

Source: Author's calculations.

The exposure determinants of significantly exposed industries estimation are reported in Tab. 5. For large manufacturing firms, both the foreign sales and turnover are important determinants. Both of the coefficients have positive value, which means the more liquid large manufacturing firms are more they are exposed. The same goes for the foreign sales. The more large manufacturing firms operate abroad, the more exposure they show. This result is consistent with Jorion, 1990 and regarding the firm size with Doige et al. (2002). Large wholesale and retail trade firms' results provide similar conclusion about the turnover, however, the foreign sales coefficient is negative, resulting in surprisingly reverse relationship between foreign sales and exposure which is consistent with Doige et al. (2002). Medium sized firms' exposure determinants analysis provided insignificant results in all cases. The small firms tend to be more exposed the less liquidity they have in case of the wholesale and retail trade activities. The relation between foreign sales 
and exposure is however positive which is consistent with Bodnar and Wong (2003). Therefore it can be assumed that there are groups of significantly exposed firms in the segments of small and large firms, depending on other factors. We can conclude that in case of large firms the more liquid they are, more exposed they will become which is consistent with theoretical expectations.

\section{Conclusion}

The paper focused on the stock prices and cash flow analysis of exchange rate exposure of Hungarian firms. The stock returns of 39 companies were used to test for the presence of exchange rate exposure of firms quoted in Budapest Stock Exchange. The exchange rate exposure was estimated by investigating the effect of changes in HUF/EUR exchange rate on stock returns during the period $2000-2014$ and separately for sub-periods from 2000 to 2006 and from 2007 to 2014 using orthogonalized market returns. Orthogonalized market returns provided in most cases better results which are consistent also with the findings that a significant number of publicly listed companies are exposed to exchange rate volatility, particularly $18.4 \%$ of companies were significantly exposed during 2007 and 2014, most of them negatively. Only $4.5 \%$ of companies were exposed during $2000-2006$ and $12.8 \%$ of companies were exposed during the all sample period. Regarding the cash flow analysis the results showed that $34 \%$ of firms are significantly exposed. When investigating the exchange rate exposure determinants it was found that market capitalization and foreign sales were important determinants of exchange rate exposure for publicly listed companies during $2007-2014$. The more the company is engaged in the international trade, the more is also exposed to exchange rate fluctuations. Turnover as a determinant of exchange rate exposure proved to be the least significant factor. The cash flow analysis provided similar results. Large firms are more exposed more liquidity they have which is consistent with theoretical expectations. The small firms operating in wholesale and retail trade industry however tend to be more exposed the less liquidity they have. Giving the high percentage of trade flows aiming to euro zone markets; these results have also implications for corporate finance. Although the financial derivatives markets are not that easily accessible by medium sized and small firms, by the time of euro adoption, the hedging against exchange rate risk would result in more effective protection of the firm value especially in case of small firms groups. The 
results indicate different exposure effects across the industries, the percentage of foreign sales and firm size and turnover are likely further important factors that determine the exchange rate exposure.

\section{References}

Adler, M. - Dumas, B. (1984): Exposure to currency risk: Definition and Measurement. Financial Management, 1984, vol. 13, no. 2, pp. 41-50.

Bartov, E. - Bodnar, G. M. (1994): Firm Valuation, Earnings, Expectations, and the Exchange-Rate Exposure Effect. The Journal of Finance, 1994, vol. 49, no. 5, pp. 1755-1785.

Bartram, S. M. - Bodnar, G. M. (2012): Crossing the lines: The Conditional Relation between Exchange Rate Exposure and Stock Returns in Emerging and Developed Markets. Journal of International Money and Finance, 2012, vol. 31, no. 4, pp. 766-792.

Bartram, S. M. - Karolyi, G. A. (2002): The Impact of the Introduction of the Euro on Foreign Exchange Rate Risk Exposures. Journal of Empirical Finance, vol. 13, no. 4-5, pp. 519-549.

Bodnar, G. M. - Marston, R. C. (2002): Exchange rate exposure: A simple model. International Finance Review, vol. 3, no., pp. 107-115.

Bodnar, G. M. - Wong, M. H. F. (2003): Estimating Exchange Rate Exposures: Issues in Model Structure. Financial Management, vol. 32, no. 1, pp. 35-67.

Booth, L. - Rotenberg, W. (1990): Assessing foreign exchange exposure: Theory and application using Canadian firms. Journal of International Financial Management and Accounting, 1990, vol. 2, no. 1, pp. 1-22.

Choi, J. J. - Prasad, A. (1995): Exchange Risk Sensitivity and Its Determinants: A Firm and Industry Analysis of U.S. Multinationals. Financial Management, 1995, vol. 24, no. 3, pp. 77-88.

Chue, T. K. - Cook, D. E. (2008): Emerging Market Exchange Rate Exposure. Journal of Banking and Finance, 2008, vol. 32, no. 7, pp. 13491362.

Dominguez, K. M. E. - Tesar, L. (2006): Exchange Rate Exposure. Journal of International Economics, 2006, vol. 68, no. 1, pp. 188-218. 
Tomanová, L.: Exchange Rate Exposure and its Determinants: Evidence on Hungarian Firms.

Doige, C. - Griffin, J. - Williamson, R. (2002): Measuring the Economic Importance of Exchange-Rate Exposure. Journal of Empirical Finance, 2002, vol. 13, no. 4-5, pp. 550-576.

Dukas, S. D. - Fatemi, A. M. - Tavakkol, A. (1996): Foreign Exchange Exposure and the Pricing of Exchange Rate Risk. Global Finance Journal, 1996, vol. 7, no. 2, pp. 171-192.

Dumas, B. - Solnik, B. (1995): The World Price of Foreign Exchange Risk. Journal of Finance, 1995, vol. 50, no. 2, pp. 445-479.

Froot, K. A. - Scharfstein, D. S., Stein, J. C. (1993): Risk management: Coordinating corporate investment and financing policies. Journal of Finance, 1993, vol. 48, no. 5, pp. 1629-1658.

Griffin, J. M. - Stulz, R. M. (2001): International Competition and Exchange Rate Shocks: A Cross-Country Industry Analysis of Stock Returns. Review of Financial Studies, 2001, vol. 14, no. 1, pp. 215-241.

Jorion, P. (1990): The Exchange-Rate Exposure of U.S. Multinationals. Journal of Business, 1990, vol. 63, no. 3, pp. 331-345.

Kiymaz, H. (2003): Estimation of Foreign Exchange Exposure: an Emerging Market Application. Journal of Multinational Financial Management, 2003, vol. 13, no.1, pp. 71-84.

Muller, A. - Verschoor, W. F. C. (2006): European Foreign Exchange Risk Exposure. European Financial Management, 2006, vol. 12, no. 2, pp. 195-220.

Priestley, R. - Odegaard, B. A. (2007): Linear and nonlinear Exchange Rate Exposure. Journal of International Money and Finance, 2007, vol. 26, no. 6, pp. 1016-1037.

Shapiro, A. (1975): Exchange rate changes, inflation, and the value of Multinational Corporation. Journal of Finance, 1975, vol. 30, no. 2, pp. 485-502.

Shapiro, A. C. (1996): Multinational Financial Management, $5^{\text {th }}$ Ed. Hoboken 


\title{
Exchange Rate Exposure and its Determinants: Evidence on Hungarian firms
}

\begin{abstract}
This paper analyses the foreign exchange rate exposure of Hungarian firms and its determinants on the basis of corporate cash flows and stock prices. The analysis focuses on the HUF/EUR exchange rate using monthly data from 2000 - 2014, resp. 2003 - 2012 in case of cash flow analysis. Stock prices exposure analysis showed that significant number of these firms is exposed: $18.4 \%$ of publicly listed companies were significantly exposed in period $2007-2014$ which is significantly higher than in previous period. According to the cash flow analysis results, $34 \%$ of firms are exposed, whilst $45.3 \%$ of small firms are significantly exposed. The measuring of exchange rate risk and hedging is therefore crucial for reduction of the firms' uncertainty. Cross-sectional analysis suggests that the turnover and foreign sales are also important determinants of firms' exchange rate exposure.
\end{abstract}

Key words: Exchange rate exposure; Stock prices; Cash flow.

JEL classification: G32, F31, C32, C31 